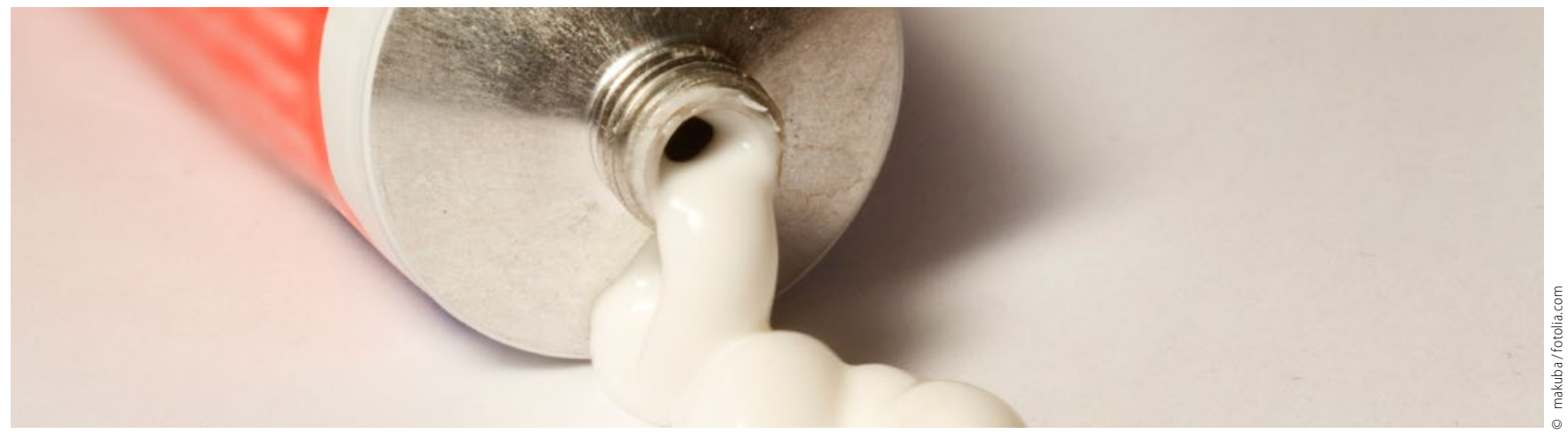

Kieferorthopädisches Urteil

\title{
Abrechenbarkeit von adhäsiver Klebetechnik bei Brackets
}

\author{
Das Amtsgericht Gießen hat sich kürzlich mit der Frage befasst, ob eine private Krankenversiche- \\ rung eine adhäsive Klebetechnik gesondert zu zahlen hat. Außerdem ging es um die Frage, ob \\ Maßnahmen zur Einstellung der Okklusion mehrfach abgerechnet werden dürfen (Urteil vom \\ 08.02.2016, Az. 41 ( 438/15).
}

\begin{abstract}
Nach Auffassung des Amtsgericht Gießen erstreckt sich der vertragliche Erstattungsanspruch der Versicherten in dem konkreten Fall über die für die Eingliederung von Klebebrackets (Nr. 6100 Gebührenordnung für Zahnärzte [GOZ]) berechneten Kosten hinaus auch auf die gemäß Nr. $2197 \mathrm{GOZ}$ gesondert in Rechnung gestellten Kosten für die adhäsive Befestigung. Die Versicherung sei deshalb nicht zur Kürzung dieser Leistung berechtigt gewesen. Die Leistungsposition Nr. 2197 GOZ sei (kumulativ) neben der Grundposition Nr. $6100 \mathrm{GOZ}$ anwendbar. Entgegen der Auffassung der Versicherung lasse sich dem Wortlaut der Leistungsposition 6100 GOZ eine abschließende Leistungsbeschreibung nicht mit hinreichender Deutlichkeit entnehmen.
\end{abstract}

\section{Besondere Befestigungsmethoden vergütungsfähig}

Soweit sich die Versicherung darauf berufe, dass sich bereits aus dem Begriff Klebebracket ergebe, dass jegliche Befestigungsarten abgegolten sei, könne dem allenfalls insofern gefolgt werden, als die Formulierung „Eingliederung" offen lässt, welche Befestigungsmethode (Zementieren oder adhäsive Befestigung) gewählt wird. Hieraus folge bei systematischer Betrachtung jedoch keineswegs ein Ausschluss der zusätzlichen Vergütungsfähigkeit besonderer Befestigungsmethoden.

Der Verordnungsgeber, dem bei Einführung der Ziffer 2197 GOZ die zu diesem Zeitpunkt bereits bestehende Leistungsziffer $6100 \mathrm{GOZ}$ bekannt war, habe durch die darin gewählte offene Formulierung „etc." klar zu erkennen gegeben, dass adhäsive Befestigungen allgemein losgelöst von dem konkreten Behandlungszusammenhang, d.h. akzessorisch (zusätzlich) zu vergüten sein sollen.

Gegen eine kumulative Anwendung beider Gebührentatbestände spreche insbesondere nicht, dass es hierdurch zu einer doppelten Vergütung von Befestigungsleistungen kommen könnte. Zum einen sei aufgrund des mit der adhäsiven Befestigung verbundenen erhöhten Aufwands nicht ersichtlich, inwieweit es tatsächlich zu einer gebührenrechtlich relevanten Doppelvergütung komme. Zum anderen seien etwaige Leistungsüberschneidungen aufgrund des typisierenden Betrachtungsansatzes der GOZ hinzunehmen.

\section{Verbesserung der Okklusion}

Die Versicherung sei darüber hinaus auch grundsätzlich zur Erstattung der wiederholt angefallenen Gebührenposition Nr. 6090 $\mathrm{GOZ}$ verpflichtet. Eine Beschränkung auf eine einmalige Abrechnung je Kiefer bestünde nicht. Mit dem Gebührentatbestand solle die intellektuelle Leistung des Zahnarztes abgegolten werden, die Okklusion mithilfe gezielter Zahnbewegung oder sonstiger Optimierungsmaßnahmen zu verbessern (vgl. Liebold/Raff/Wissing, GOZ, Nr. 6090, Rn. 1). Der Gebührentatbestand sei dementsprechend tätigkeitsbezogen und während der Dauer der Behandlung daher mehrfach (je Kiefer) quartalsweise abrechenbar.

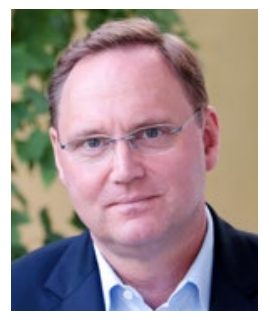

RA Michael Lennartz

www.lennmed.de 